\title{
Notes on three scandals
}

\author{
Fiona Godlee editor in chief
}

The BMJ

Medicine has its fair share of scandals. This week The BMJ reports on three. First, cardiologists John Dean and Neil Sulke highlight what they see as the scandal of the short life of pacemaker batteries (doi:10.1136/bmj.i228). Over half of patients with pacemakers will need new batteries, they say, and many need several replacements. But there are no incentives to develop longer life devices. Increasing longevity would reduce profits for manufacturers, implanting physicians, and their institutions, they say. Meanwhile, patients risk infection and other complications of replacement, and money is wasted replacing batteries before they've expired.

The second scandal is a more deep seated one: medicine's failure to act when members flout basic codes of probity and competence. In the extraordinary saga, doggedly pursued by Peter Wilmshurst for nearly 20 years, surgeon Anjan Kumar Banerjee was briefly awarded an MBE despite having been struck off for serious professional and research misconduct (doi:10.1136/bmj.h6952). He still retains fellowships from three royal colleges and a masters degree that was based on fraudulent data.

Uncovering a bizarre catalogue of failures, Wilmshurst finds rot in almost every pillar of the medical establishment: the universities, the GMC, the royal colleges, the medical honours system - all opaque to scrutiny and resistant to accountability. "When errors occur, the establishment would usually rather close ranks and silence whistleblowers than correct the error," says Wilmshurst. We need, he says, to get rid of the existing "club culture" in British medicine and create instead a culture that values integrity and transparency.

In his linked editorial (doi:10.1136/bmj.i293), the former BMJ editor Richard Smith has understandably given up hope of change from within the profession. "Something is rotten in the state of British medicine and has been for a long time," he says. What we need is "a statutory body with powers that can oversee research institutions, including universities."

Our third scandal reflects an equally longstanding malaise, this time in drug development. Deborah Cohen has been on the trail of the evidence behind the new direct oral anticoagulants for three years. Her first report found hidden evidence of a therapeutic range for dabigatran, undermining claims that patients taking these new drugs don't need regular blood checks (doi:10.1136/bmj.g4670). Further digging by Cohen has uncovered use of a faulty monitoring device in the only pivotal trial of rivaroxaban, casting serious doubt on findings that underpin use of what is now the world's best selling new oral anticoagulant (doi:10.1136/bmj.i575). Efforts to allow independent analysis of the data have so far failed.

To paraphrase Smith's conclusion, things will go wrong in medicine. The real scandal is in failing to act properly when they do.

\section{Cite this as: BMJ 2016;352:i674}

๑ BMJ Publishing Group Ltd 2016 